\title{
Decompression of the Spinal Cord Improves Recovery after Acute Experimental Spinal Cord Compression Injury
}

\author{
A. Guha, ${ }^{1}$ C. H. Tator, ${ }^{2}$ L. Endrenyi, ${ }^{3}$ I. Piper $^{4}$ \\ ${ }^{1}$ Fellow of the Medical Research Council of Canada, Division of Neurosurgery and \\ Playfair Neuroscience Unit, Toronto Western Hospital, University of Toronto, \\ Canada, ${ }^{2}$ Prof. of Neurosurgery, Spinal Cord Injury Treatment and Prevention \\ Centre and Playfair Neuroscience Unit, 399 Bathurst Street, Toronto Western \\ Hospital, University of Toronto, Toronto, Ontario, Canada M5T 2S8, ${ }^{3}$ Prof. of \\ Pharmacology, University of Toronto, Canada, ${ }^{4}$ Research Technician, Division \\ of Neurosurgery and Playfair Neuroscience Unit Toronto Western Hospital, \\ University of Toronto, Canada
}

\section{Summary}

The value of decompression after spinal cord injury in patients is still an unresolved issue. It has previously been shown in our laboratory that functional recovery in rats after cord compression varied with both the force and time until decompression. However, the longest duration studied was only 15 minutes, which is far less than that usually encountered in clinical practice, and therefore, the present study was undertaken to determine the value of decompression after more prolonged periods of compression.

$A$ factorially designed experiment with five rats per cell was used with the clip compression injury model. Forces of $2.3,16.9$ or 53.0 gms were applied at C7-T1 until decompression was performed after 15, 60, 120, or 240 minutes of compression. Functional recovery was assessed weekly for 8 weeks using the inclined plane technique. Maximum and minimum performance limits were established in normal rats and rats with cord transection, respectively. Univariate analysis and multiple comparison tests were used to analyse the data.

The major determinant of recovery was the force of the injury. For example, the animals injured by the $2.3 \mathrm{gm}$ clip performed significantly better than those injured at higher forces for all times until decompression $(p<0.0001)$, and there was a significant difference in recovery between the groups injured by the 16.9 and 53.0 gm clips, although only for the 15 minutes until decompression group $(p<0.05)$. The time until decompression also affected recovery, but only for the lighter compression forces $(2.3$ and $16.9 \mathrm{gm})$. For example, animals decompressed after 60 minutes of $2.3 \mathrm{gm}$ compression recovered significantly better than those decompressed after 240 minutes $(p<0.05)$. Thus, if the initial injury force is small, decompression is beneficial even after prolonged injury.

Key words: Experimental spinal cord injury; Force of injury; Decompression; Neurological recovery

Correspondence to Dr C. H. Tator, Spinal Cord Injury Treatment, Research and Prevention Centre, Toronto Western Hospital, 399 Bathurst Street, Toronto, Ontario, Canada M5T 2S8 


\section{Introduction}

Decompression after acute spinal cord trauma may be defined as the relief of persistent pressure within or on the spinal cord by surgical and/or non-surgical intervention. Non-surgical decompression may involve reduction of dislocation by traction, or reduction of spinal cord swelling by pharmacological agents such as steroids or diuretics. Surgical decompression may be performed by a variety of surgical approaches to the spine and spinal cord, and may include operative reduction of dislocation or removal of impinging bone or disc. In spinal cord trauma with complete sensory loss and paralysis, it is generally agreed that decompression after 24 hours is not efficacious in promoting neurological recovery of cord function while the value of decompression before this time is still controversial (Ducker, Bellegarrigue, Saloman, Walleck, 1984; Stauffer, 1975; Tarlov, Klinger, 1954). With incomplete injuries of the cord, and with all cauda equina injuries, there is also controversy about the role of decompression after any time interval. The interaction between the magnitude or force of the initial injury, the time until decompression, and the ultimate neurological recovery is not fully understood. Indeed, clinical decisions regarding decompression are often made on an empirical basis rather than on established clinical and laboratory data.

Tarlov, in the late 1950's attempted to define the thresholds for the strength of injury and the duration of compression below which neurological recovery could still occur after decompression of the spinal cord (Tarlov, 1972; Tarlov, Kinger, Vitale, 1953; Tarlov, Klinger, 1954; Tarlov, 1954). He used epidural balloons of different sizes to compress the canine thoracic spinal cord, and concluded that the time until decompression was an important factor in determining the final neurological deficit. Accordingly, he recommended decompression as early as possible. In our laboratory, Dolan et al. (1980), studied the relationship between force, time until decompression and recovery, and generated recovery curves for the clip compression injury model in rats. Three clip strengths were studied until decompression at five periods of time, the longest of which was 15 minutes. It was found that time until decompression was a significant determinant of neurological recovery for all clip strengths studied. However, 15 minutes is usually much less time than is required for a patient with a spinal cord injury to reach a medical setting where definitive treatment can be undertaken. Thus, the present study was designed to determine whether decompression can still improve functional recovery after clinically relevant times until decompression. In these studies, decompression was simulated by removal of a clip compressing the spinal cord.

\section{Methods}

\section{Operative procedure and injury model}

Female Wistar rats (240-280 gms; Charles River, Canada Inc.) were anaesthetised with sodium pentobarbital, $30 \mathrm{mg} / \mathrm{kg}$ intraperitoneal (i.p.) with an additional $20 \mathrm{mg} / \mathrm{kg}$ i.p. dose after 2 hours for the animals undergoing 240 minutes of compression. The $\mathrm{C} 7$ and $\mathrm{T} 1$ laminae were removed and the spinal 
cord injured using the clip compression injury model described previously by Rivlin and Tator (1978). The injury was made at C7-T 1 by a modified aneurysm clip (Fig. 5) passed extradurally around the spinal cord to a consistent distance from the fulcrum of the clip. The injury was made by rapidly releasing the clip from a standardised position in the aneurysm clip applicator. The steel C springs of the clip varied in thickness and tensile strength (Fig. 5), and this determined the magnitude of the injury. Clip strengths were measured by a modification of the technique of Dolan et al. (1979), and there were no significant differences in clip strength $(p>0.05)$ before and after completion of the experiments for any of the three clips, indicating that there was no weakening of the clips during the experiments. The time until decompression was altered by allowing the clip to compress the spinal cord for a specified time before decompression of the cord by removal of the clip with the applicator. One group of animals underwent complete transection of the spinal cord with a No. 15 scalpel at C7-T1. The transection was continued until the posterior aspect of the vertebral body was visualised under the Zeiss operating microscope.

After injuring the spinal cord and obtaining haemostasis, the wound was irrigated with saline and the paraspinal muscles closed with 3-0 Dexon. The skin was approximated with staples and and the animals returned to their cages in a $30^{\circ} \mathrm{C}$ environment. Manual bladder expressions were carried out three times daily, and urinary tract infections were treated by increasing the frequency of bladder expressions.

\section{Assessment}

The inclined plane technique (Rivlin, Tator, 1977) was used to evaluate functional recovery. The angle achieved on the inclined plane was recorded weekly in a 'blind' fashion for eight weeks excluding the first week after injury. The evaluations were performed without knowledge of the group to which individual animals belonged.

\section{Experimental protocol}

Three clip strengths $(2.3,16.9$ and $53.0 \mathrm{gm})$ were studied until decompression $(15,60,120$ and $240 \mathrm{~min})$ at four periods of time in a three by four factorial design experiment composed of 12 cells. Each cell contained five rats, randomly assigned to that particular cell. In addition, 10 normal rats and five with complete cord transection at C7-T1, the same spinal segment at which the acute compression injury was made, were used to determine the upper and lower limits of neurological function respectively on the inclined plane.

\section{Analysis}

The maximum and minimum inclined plane results were calculated by averaging the angles achieved over the full 8 weeks by the normal and cord transected animals respectively. The weekly average angle achieved by the five animals in each group was calculated for each clip strength (Fig. 1A, B, C). In addition, the overall average angle for the 8 weeks for each group (Table I), was plotted against 
Table I Weeks 1-8. Mean angle $\left(^{\circ}\right) \pm$ SEM scored on the inclined plane for Weeks 1-8, for different clip strengths and times until decompression. Upper (Normal) and lower (Spinal Cord Transected) limits of performance are shown

\begin{tabular}{cccc}
\hline $\begin{array}{c}\text { Time until } \\
\text { decompression } \\
\text { (minutes) }\end{array}$ & $2 \cdot 3$ & $\begin{array}{c}\text { Clip strength } \\
(\mathrm{gm})\end{array}$ \\
\cline { 2 - 4 } & $65 \cdot 4^{\circ} \pm 0 \cdot 9^{\circ}$ & $39 \cdot 4^{\circ} \pm 3 \cdot 0^{\circ}$ & $30 \cdot 9^{\circ} \pm 1 \cdot 1^{\circ}$ \\
60 & $62 \cdot 0^{\circ} \pm 1 \cdot 2^{\circ}$ & $33 \cdot 1^{\circ} \pm 1 \cdot 2^{\circ}$ & $32 \cdot 1^{\circ} \pm 1 \cdot 2^{\circ}$ \\
15 & $52 \cdot 0^{\circ} \pm 1 \cdot 5^{\circ}$ & $34 \cdot 3^{\circ} \pm 1 \cdot 5^{\circ}$ & $33 \cdot 1^{\circ} \pm 2 \cdot 8^{\circ}$ \\
240 & $53 \cdot 3^{\circ} \pm 1 \cdot 8^{\circ}$ & $32 \cdot 0^{\circ} \pm 2 \cdot 2^{\circ}$ & $32 \cdot 0^{\circ} \pm 1 \cdot 5^{\circ}$ \\
\hline
\end{tabular}

Normal $=81 \cdot 4^{\circ} \pm 1 \cdot 8^{\circ}$. Spinal cord transection $=29 \cdot 2^{\circ} \pm 2 \cdot 2^{\circ}$.

clip strength (Fig. 2) and against time until decompression (Fig. 3). One way analysis of variance was used to determine if clip strength or time until decompression significantly affected the angle achieved (Table II). Multiple comparison testing using the Student-Newman-Keuls test at a significance level

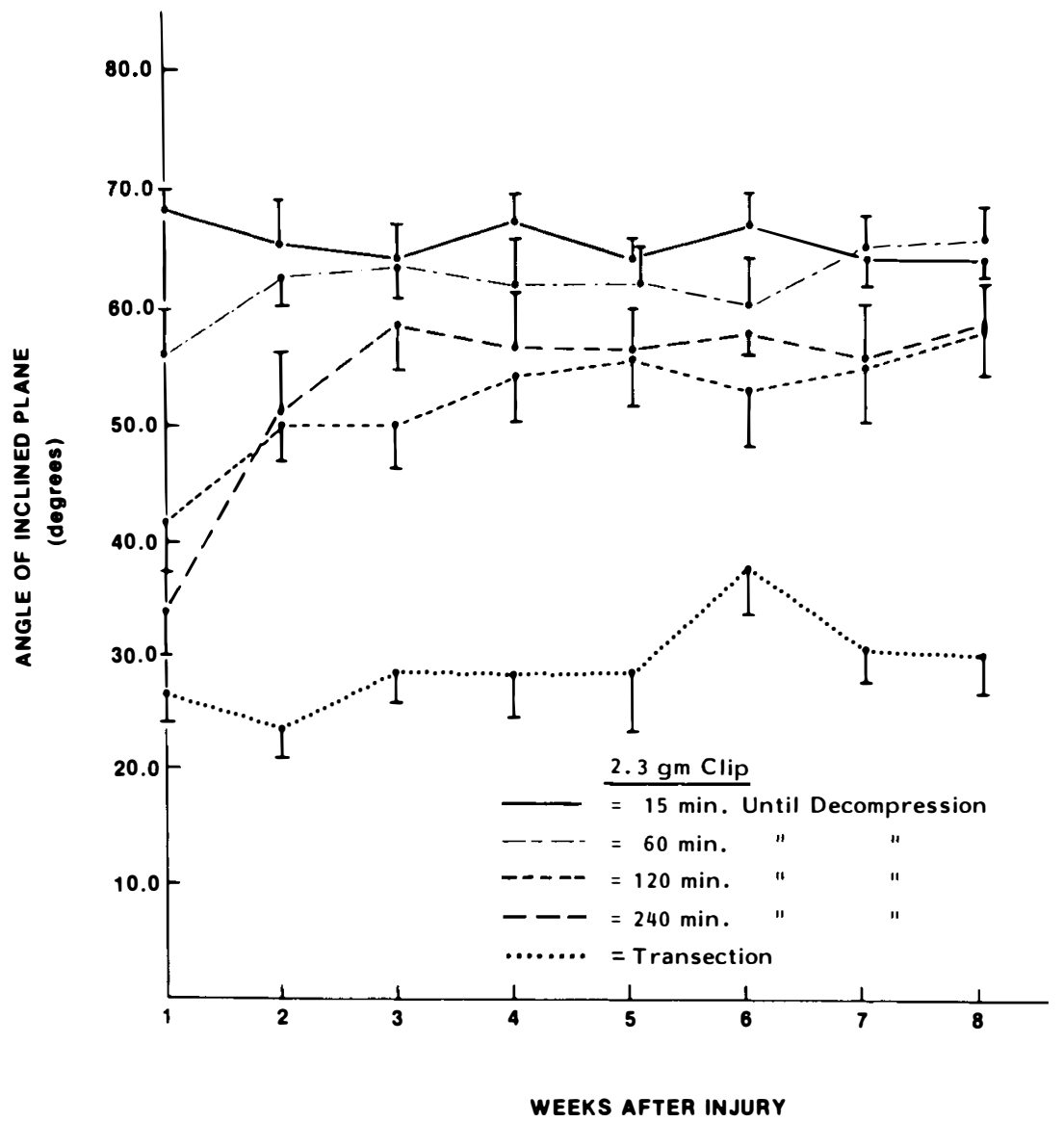

Figure 1 Average weekly inclined plane scores with standard errors are shown for the three clip strengths $2.3 \mathrm{gm}(\mathrm{A}), 16.9 \mathrm{gm}(\mathrm{B})$ and $53.0 \mathrm{gm}(\mathrm{C})$ for each of the four times until decompression (15, 60, 120 and 240 minutes). The average weekly angle scored by the animals with a total spinal cord transection is also plotted in Fig. 1A. 
Table II Analysis of variance results, F values, correlation coefficient $\left(\gamma^{2}\right)$ and P Values. Table IIA tests for differences in performance on the inclined plane between clip strengths at various times until decompression. Table IIB tests for differences in performance between times until decompression for various clip strengths. ${ }^{\star}=$ Significant at $\mathrm{p}=\cdot 05$

\begin{tabular}{lccccccc}
\hline & IIA & $\begin{array}{c}\text { Time until decompression } \\
\text { (minutes) }\end{array}$ & & IIB & \multicolumn{2}{c}{$\begin{array}{c}\text { Clip strength } \\
(\mathrm{gm})\end{array}$} \\
\cline { 2 - 8 } Analysis & 15 & 60 & 120 & 240 & $2 \cdot 3$ & $16 \cdot 9$ & $53 \cdot 0$ \\
\hline $\mathrm{F}$ & $91 \cdot 51$ & $198 \cdot 21$ & $36 \cdot 23$ & $51 \cdot 54$ & $14 \cdot 08$ & $3 \cdot 06$ & $0 \cdot 29$ \\
$\begin{array}{l}\text { (Degrees of } \\
\text { freedom) }\end{array}$ & $(2124)$ & $(2131)$ & $(2147)$ & $(2147)$ & $(3241)$ & $(3164)$ & $(3144)$ \\
$\gamma^{2}$ & .596 & .752 & .330 & .412 & .149 & .053 & .006 \\
$P$ & $.0001 \star$ & $.0001 \star$ & $.0001 \star$ & $.0001 \star$ & $.0001 \star$ & $.0294^{\star}$ & $.8321^{\star}$ \\
\hline
\end{tabular}

of alpha $=.05$ was done to isolate significant differences between the various clip strengths and times until decompression (Table III).

Recovery 'surfaces' (Fig. 4), relating angle achieved to clip strength and times until decompression were generated using the Statistical Analysis System

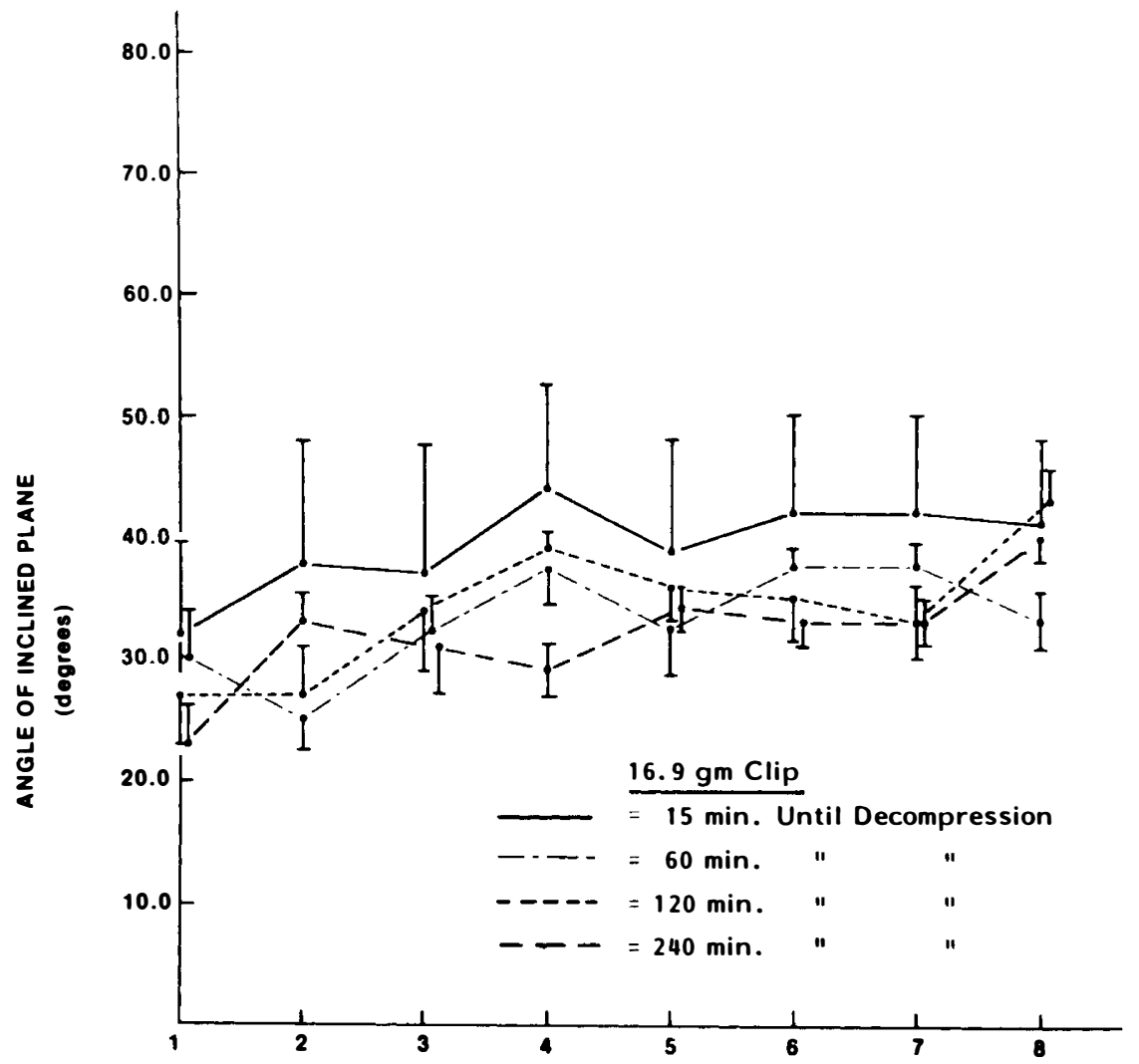

WEEKS AFTER INJURY

Figure 1B 


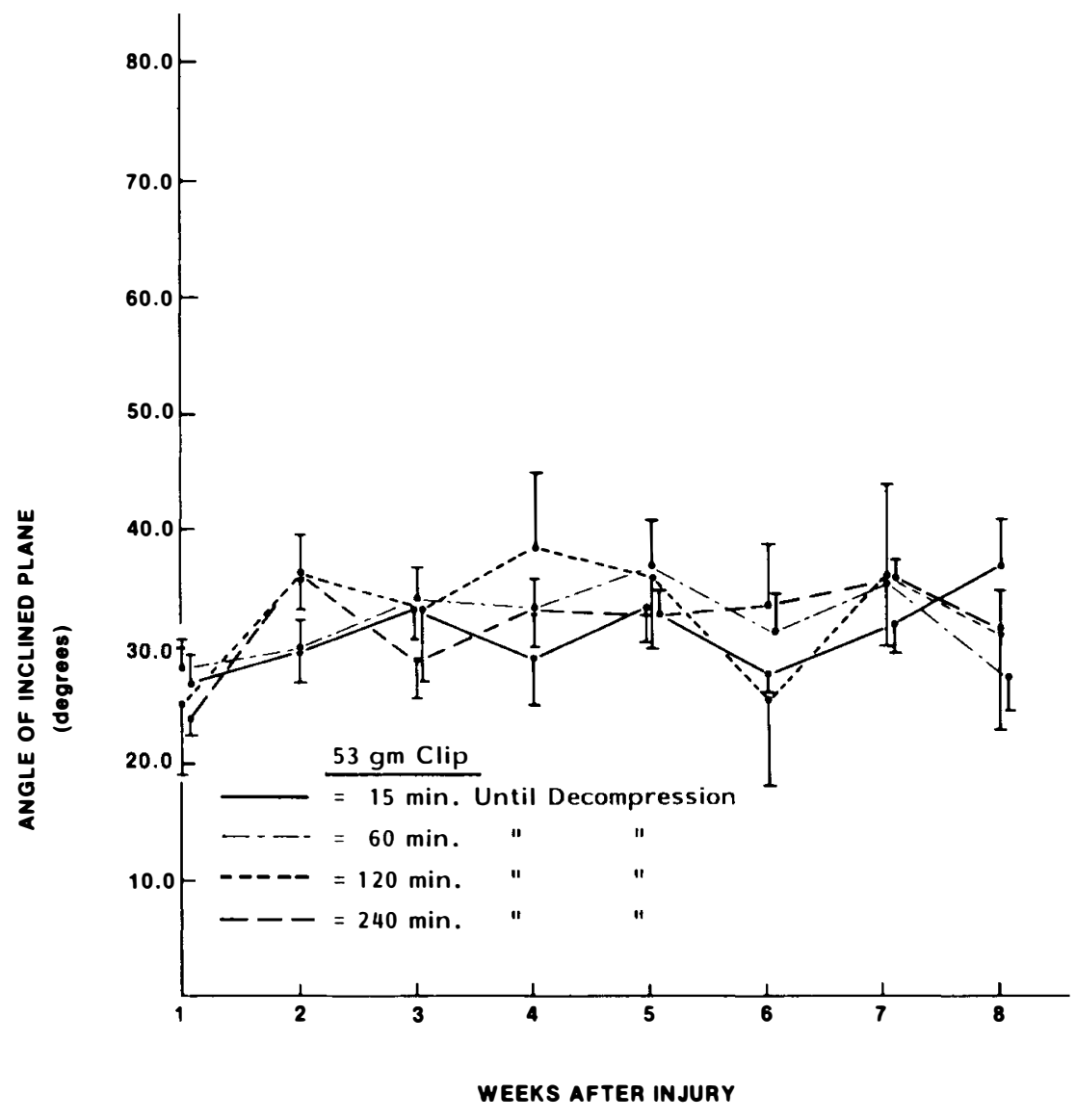

Figure 1C

programme (Cary, N. Carolina, U.S.A.) run on a IBM 370 computer (University of Toronto Computer System, Canada). This was done for the first week, and for the combined overall average for the second to eighth weeks for each group (Table IV).

\section{Results}

The intensity of cord compression increased with clip strength and could be seen under the operating microscope at the time of clip compression. To demonstrate this, a 2.3 and 53.0 gm clip were applied extradurally to a freshly harvested rat spinal cord at C7-T1 and it can be seen that the $53.0 \mathrm{gm}$ clip produced much more compression and distortion of the cord (Fig. 5). Indeed, the blades of the $53.0 \mathrm{gm}$ clip almost came together. In addition, the extent of blanching of the dorsal veins, and the amount of subpial hemorrhage observed microscopically increased with clip strength. Intramedullary haemorrhage could 
Table III Duncan's multiple comparison test results at $\mathrm{p}=\cdot 05$. Groups in a given column not joined with the same letter differ in performance on the inclined plane. Table IIIA examined differences between clip strengths for each time until decompression. Table IIIB examines differences between times until decompression for each clip strength

IIIA

\begin{tabular}{ccccc}
\hline $\begin{array}{c}\text { Clip } \\
\text { strength } \\
\text { (gm) }\end{array}$ & 15 & 60 & \multicolumn{3}{c}{$\begin{array}{c}\text { Time until decompression } \\
\text { (minutes) }\end{array}$} \\
\hline 2.3 & A & A & A & A \\
16.9 & B & B & B & B \\
53.0 & C & B & B & B \\
\hline
\end{tabular}

\begin{tabular}{|c|c|c|c|}
\hline \multirow{2}{*}{$\begin{array}{l}\text { Time until } \\
\text { decompression } \\
\text { (minutes) }\end{array}$} & \multicolumn{3}{|c|}{$\begin{array}{l}\text { Clip strength } \\
(\mathrm{gm})\end{array}$} \\
\hline & $2 \cdot 3$ & 16.9 & 53.0 \\
\hline 15 & $\bar{A}$ & A & $\overline{\mathrm{A}}$ \\
\hline 60 & A & B & A \\
\hline 120 & B & B & A \\
\hline 240 & B & B & A \\
\hline
\end{tabular}

be observed through the surface of the spinal cord with all clip strengths but was more marked with increasing strength.

During the 8 week period, the normal animals and the animals with spinal cord transection averaged $81.4 \pm 1 \cdot 8^{\circ}$ and $29 \cdot 2 \pm 2 \cdot 2^{\circ}$ respectively on the inclined plane. Figure 1 shows the weekly performance of the 12 groups of animals injured with the clips of three strengths and four different times until decompression. The animals injured with the lightest clips $(2 \cdot 3 \mathrm{gm})$ at all four durations achieved significantly lower scores than the normal animals $(\mathrm{p}<\cdot 05)$ (Fig. 1A). Except for the group injured with the $16.9 \mathrm{gm}$ clip for 15 minutes, all animals injured with the 16.9 or 53.0 gm clips did not achieve angles significantly different from the fully transected group $(\mathrm{p}>\cdot 05)$ (Figs. 1B and C).

As seen in Figure 2 and Table I, clip strength was the main determinant of neurological recovery. Indeed, there was a dramatic drop in function between the groups injured with the $2.3 \mathrm{gm}$ and $16.9 \mathrm{gm}$ clips for all durations. The dominant effect of clip strength on function was verified statistically using analysis of variance where it was highly significant for all durations $(\mathrm{p}<\cdot 0001)$ (Table IIA). Multiple comparison testing showed that when the time until decompression was 15 minutes, the angle achieved was significantly different between all three clip strengths $(\mathrm{p}<\cdot 05)$ (Table IIIA), whereas, at longer durations the results obtained with the 16.9 and $53.0 \mathrm{gm}$ clips did not differ. The groups injured at $2.3 \mathrm{gm}$ were statistically better for all durations $(\mathrm{p}<\cdot 05)$ than the groups injured at 16.9 or $53.0 \mathrm{gm}$.

The time until decompression was a significant determinant of function only for the 2.3 amd $16.9 \mathrm{gm}$ clips ( $\mathrm{p}<\cdot 05$ ) (Table IIB). Multiple comparison testing 


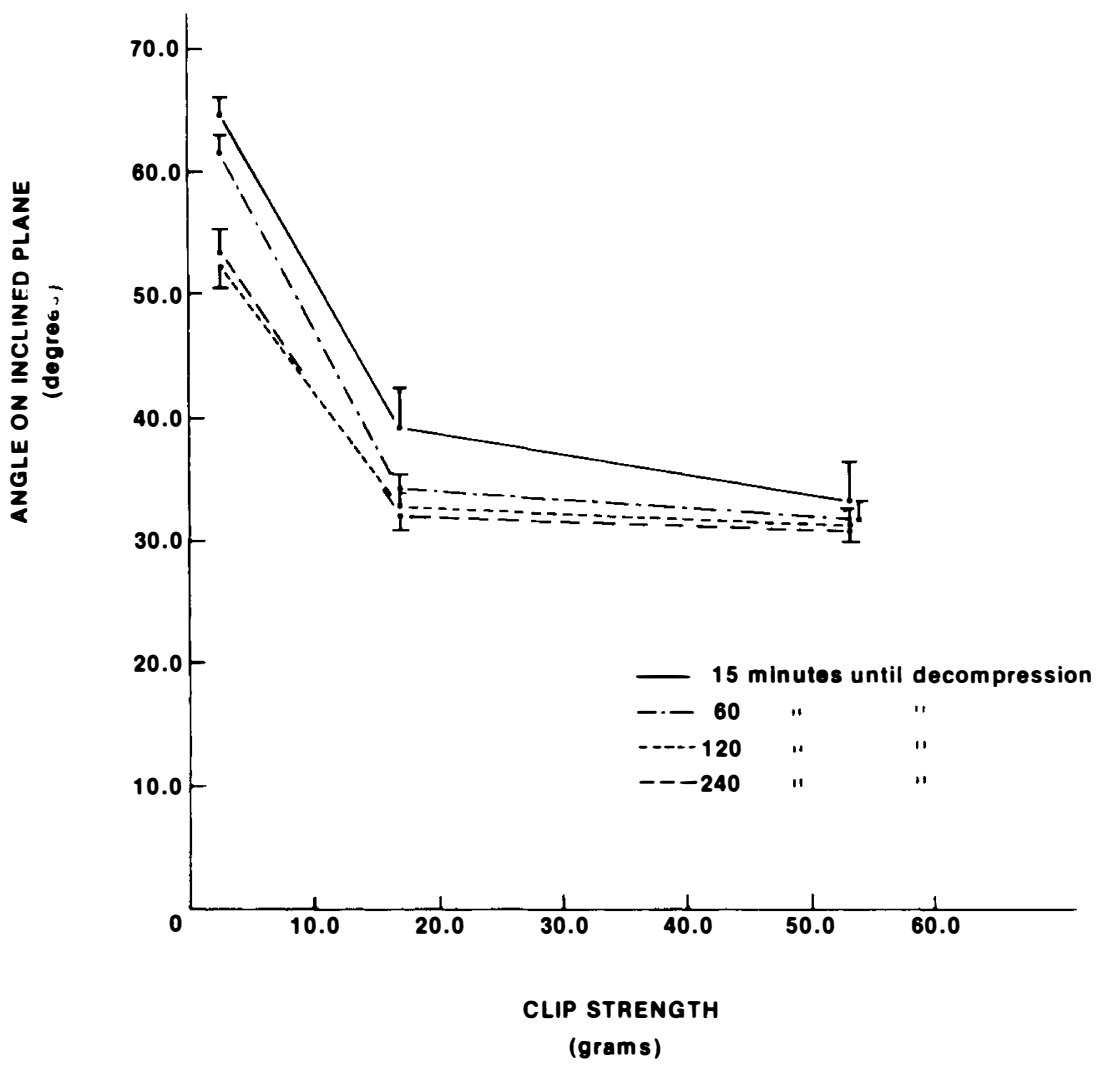

Figure 2 The average scores with standard errors on the inclined plane for weeks 1-8 are plotted against clip strength (gm) for each time until decompression (minutes). The figure shows that the clip strength was the main determinant of angle scored, although the time until decompression also affected the results with the weaker clips.

showed that at $2.3 \mathrm{gm}$, the animals decompressed after 15 or 60 minutes of compression had significantly better function than those decompressed after longer periods $(\mathrm{p}<\cdot 05)$ (Table IIIB). With the $16.9 \mathrm{gm}$ injury, recovery was enhanced only if the decompression occurred at 15 minutes $(p<\cdot 05)$. In contrast, early decompression did not significantly improve function in the animals injured with the 53.0 gm clip $(\mathrm{p}<0.5)$. Figure 3 shows the angle achieved on the inclined plane plotted against time until decompression. With the 2.3 injury, the animals showed a linear decrease in function with increasing time until decompression up to 120 minutes, after which there was no apparent further deterioration. For the $16.9 \mathrm{gm}$ clip there was a decrease in function if decompression was not undertaken within 15 minutes. Conversely, the time until decompression did not affect the performance of the animals injured with the $53.0 \mathrm{gm}$ clip (as shown by the horizontal line in Figure 3).

The computer-generated, three-dimensional representation of the interaction between recovery of neurological function (angle on inclined plane, clip strength 


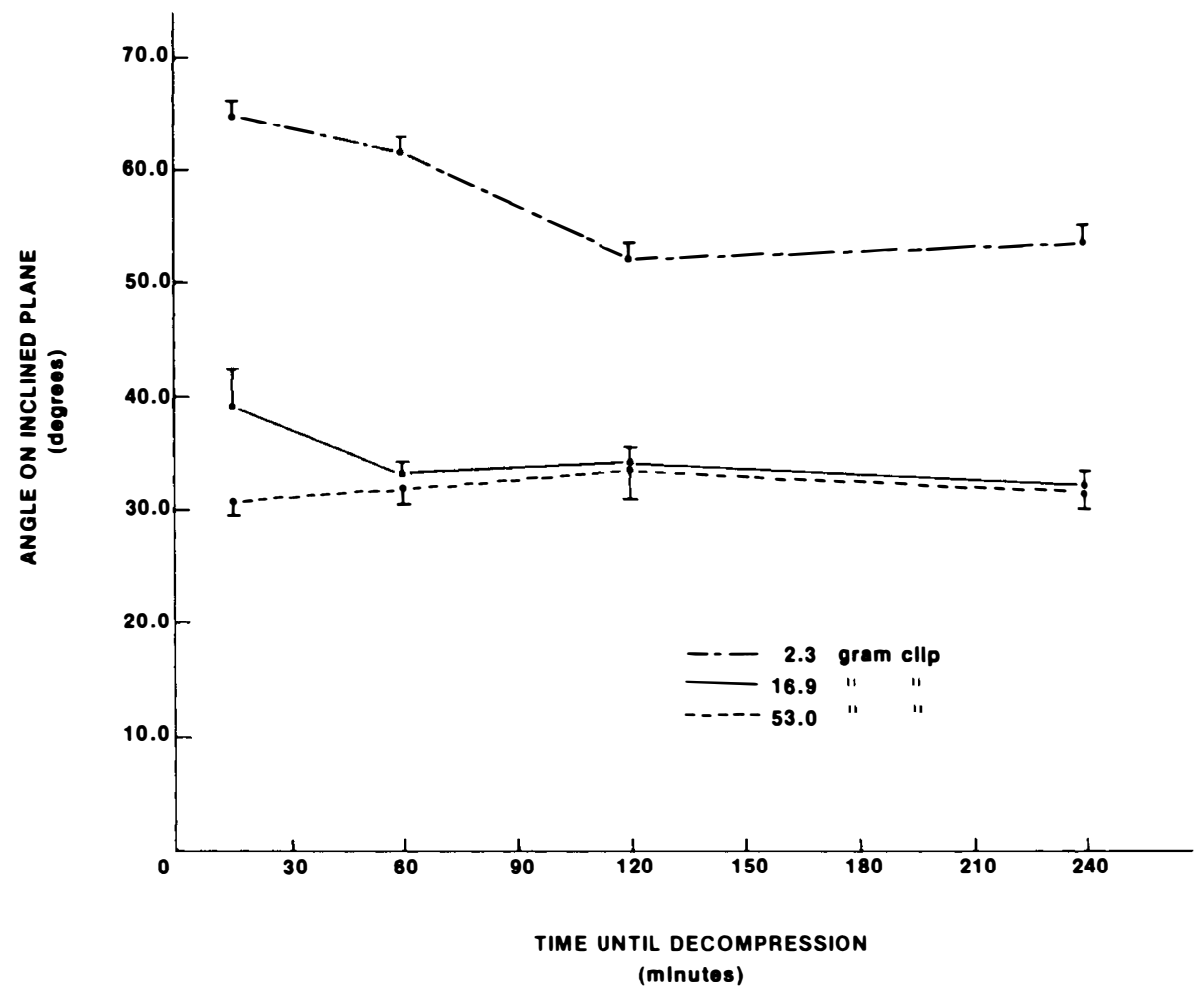

Figure 3 The average scores with standard errors on inclined plane for weeks 1-8 are plotted against the time until decompression (minutes) for the three clip strengths $(2 \cdot 3,16 \cdot 0,53 \cdot 0 \mathrm{gm})$. With the $2.3 \mathrm{gm}$ clip the angle scored decreased with increasing time until decompression. With the 16.9 gm clip, the angle remained constant from 60 to 240 minutes, and with the $53.0 \mathrm{gm}$ clip the time until decompression did not influence the angle scored.

Table IV Mean angle $\left(^{\circ}\right) \pm$ SEM for Week 1 (IVa) and Weeks 2-8 (IVb) scored on the inclined plane for different clip strengths and times until decompression. Values were used to computer generate the respective recovery surface, (Fig. 4)

\section{IVA Week 1}

\begin{tabular}{|c|c|c|c|}
\hline \multirow{2}{*}{$\begin{array}{l}\text { Time until } \\
\text { decompression } \\
\text { (minutes) }\end{array}$} & \multicolumn{3}{|c|}{$\begin{array}{l}\text { Clip strength } \\
\text { (gm) }\end{array}$} \\
\hline & $2 \cdot 3$ & $16 \cdot 9$ & $53 \cdot 0$ \\
\hline 15 & $68 \cdot 0^{\circ} \pm 2 \cdot 0^{\circ}$ & $32.0^{\circ} \pm 8.5^{\circ}$ & $26 \cdot 7^{\circ} \pm 2 \cdot 8^{\circ}$ \\
\hline 60 & $55 \cdot 8^{\circ} \pm 4 \cdot 4^{\circ}$ & $30 \cdot 0^{\circ} \pm 4 \cdot 1^{\circ}$ & $28.0^{\circ} \pm 2.5^{\circ}$ \\
\hline 120 & $41 \cdot 5^{\circ} \pm 4 \cdot 7^{\circ}$ & $27 \cdot 0^{\circ} \pm 4 \cdot 4^{\circ}$ & $25 \cdot 0^{\circ} \pm 6 \cdot 8^{\circ}$ \\
\hline 240 & $33 \cdot 5^{\circ} \pm 6 \cdot 3^{\circ}$ & $23 \cdot 0^{\circ} \pm 3 \cdot 0^{\circ}$ & $23.8^{\circ} \pm 1.3^{\circ}$ \\
\hline \multicolumn{4}{|l|}{ Weeks 2-8 } \\
\hline \multirow{2}{*}{$\begin{array}{l}\text { Time until } \\
\text { decompression } \\
\text { (minutes) }\end{array}$} & & $\begin{array}{l}\text { Clip strength } \\
\text { (gm) }\end{array}$ & \\
\hline & $2 \cdot 3$ & $16 \cdot 9$ & $53 \cdot 0$ \\
\hline 15 & $65.0^{\circ} \pm 1.4^{\circ}$ & $40 \cdot 4^{\circ} \pm 2 \cdot 5^{\circ}$ & $34.3^{\circ} \pm 3 \cdot 2^{\circ}$ \\
\hline 60 & $62 \cdot 9^{\circ} \pm 2 \cdot 0^{\circ}$ & $35 \cdot 3^{\circ} \pm 4 \cdot 6^{\circ}$ & $33.2^{\circ} \pm 3.4^{\circ}$ \\
\hline 120 & $56 \cdot 3^{\circ} \pm 2 \cdot 9^{\circ}$ & $33 \cdot 6^{\circ} \pm 5 \cdot 0^{\circ}$ & $32 \cdot 7^{\circ} \pm 4 \cdot 6^{\circ}$ \\
\hline 240 & $53 \cdot 6^{\circ} \pm 2 \cdot 6^{\circ}$ & $33 \cdot 3^{\circ} \pm 3 \cdot 4^{\circ}$ & $31 \cdot 6^{\circ} \pm 2 \cdot 7^{\circ}$ \\
\hline
\end{tabular}




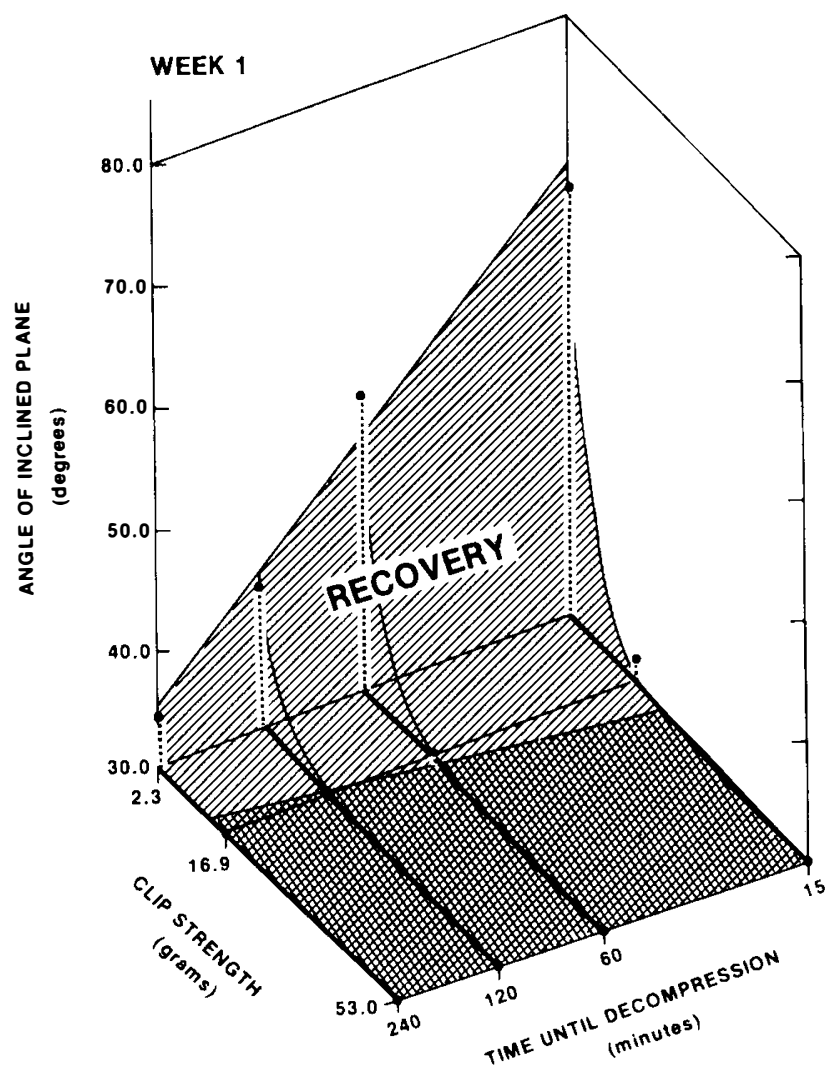

Figure 4 Computer generated 'recovery surfaces' relating angle on the inclined plane, clip strength (gm) and time until decompression (minutes). Actual data points are marked by a dot. (A) shows the 'surface' for results at 1 week after injury and (B) shows the 'surface' for the values averaged for weeks $2-8$. The 'recovery surface' declines sharply as the clip strength increases, while it slopes down more gradually with increasing time until decompression.

and time until decompression is shown in Figure 4. The 'surface' of this graph may be conceived as depicting functional recovery. The graphs of the results at 1 week after injury (Fig. 4A) and of the averaged results for the second to eighth week after injury (Fig. 4B) both show a sharp exponential decay in function with increasing force, and a much gentler linear decay of function with increasing time until decompression. This is a reflection of the fact that the major determinant of recovery was the clip strength. The recovery surface of both graphs levels off at the baseline which is the angle achieved by the animals with spinal cord transection. This implies that more severely injured animals did not recover better than the animals with complete cord transection. However, there is a slight elevation of the recovery surface for weeks $2-8$ (Fig. $4 \mathrm{~b}$ ) as compared with the first week (Fig. 4A) which indicates that there was some improvement during the second to eighth week after injury. The recovery surface for week 8 only (not shown) was very similar to that for weeks $2-8$. 


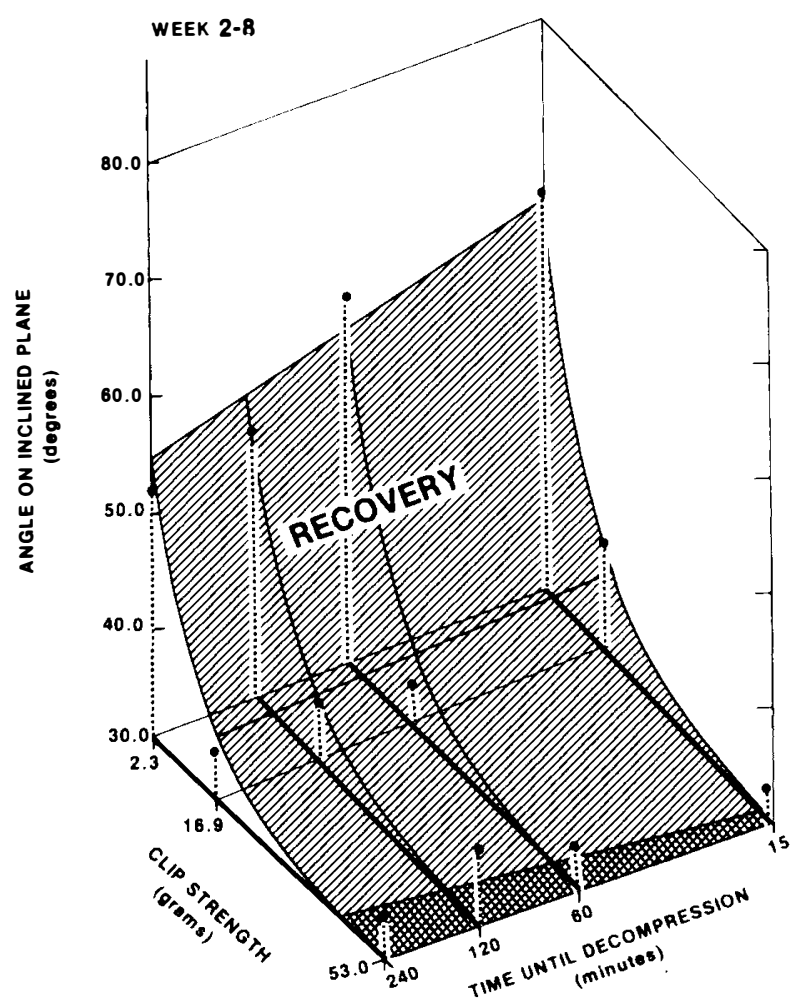

Figure 4B

\section{Discussion}

Persisting compression of the spinal cord after trauma may be due to either internal or external factors or both. Internal pressure may be the result of oedema or haematomyelia, while external pressure may be due to encroachment on the spinal cord by bone, disc or blood. Internal decompression or relief of the internal pressure by pharmacological agents such as steroids or diuretics have been investigated (Ducker et al., 1969; 1978), though definitive proof of their efficacy in promoting neurological recovery in patients is still lacking. Similarly durotomy or myelotomy to relieve internal pressure have not been proven to be beneficial in patients since they were initially advocated by Allen (1914).

Trauma to the spinal cord in patients usually involves both an initial impact followed by persisting compression by an intracanalicular space occupying lesion, usually bone, which encroaches upon the spinal canal. The exception is a dislocation which spontaneously and immediately becomes reduced, and in our opinion, this is rare. The clip compression injury model used in this study simulates both the initial impact as well as the persisting compression produced by a fracture dislocation without spontaneous reduction, which is the commonest mechanism of spinal cord injury in man. In contrast, the Allen technique 


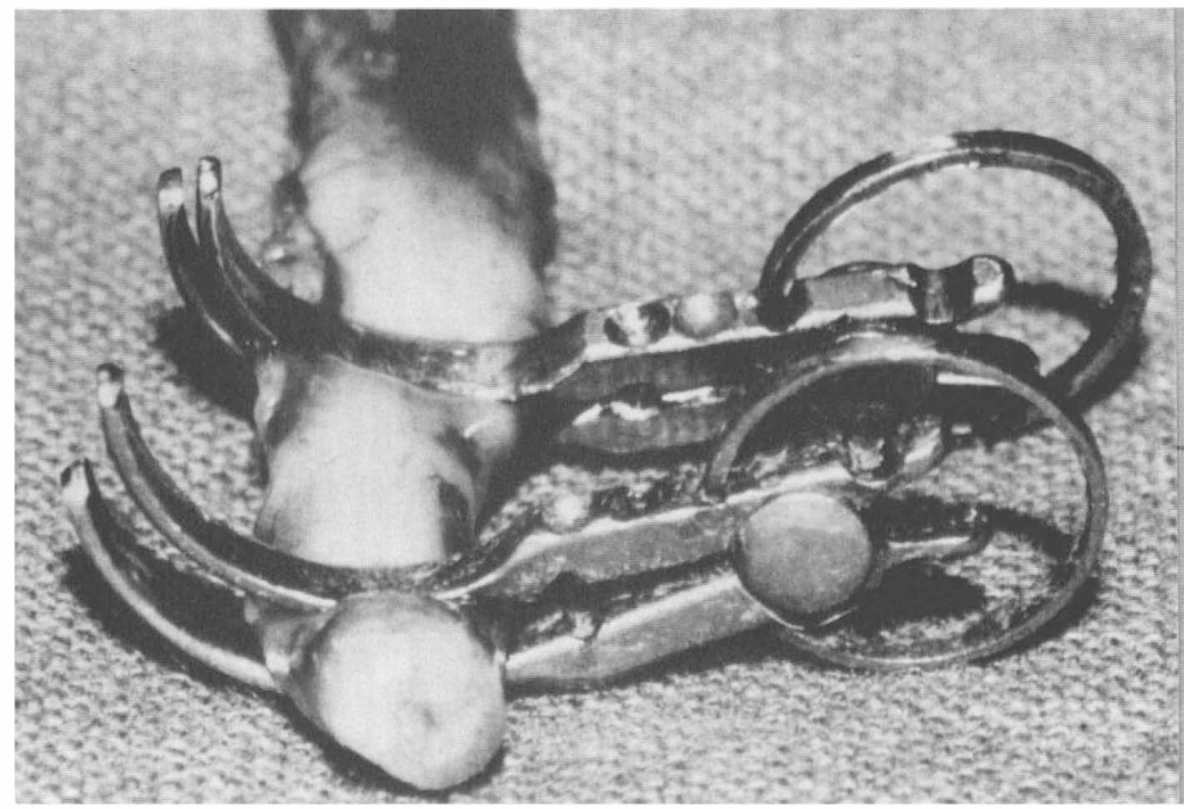

Figure 5 Two compression clips have been applied to a freshly harvested rat spinal cord at the $\mathrm{C} 7-\mathrm{T} 1 \mathrm{region}$. The $2.3 \mathrm{gm}$ clip in the foreground compressed the cord to a lesser extent than the $53.0 \mathrm{gm}$ clip in the middleground. Indeed blades of the $53.0 \mathrm{gm}$ clip are almost touching each other. This gross difference in the amount of compression correlated well with the angle scored on the inclined plane. The $\mathrm{C}$ spring of the $53.0 \mathrm{gm}$ clip is much thicker than spring of the $2 \cdot 3$ gm clip.

(Allan, 1914), which involves dropping a weight from a height on to the exposed spinal cord simulates only the initial impact and omits the persisting compression. What portion of the ultimate neurological deficit in patients is due to the initial impact and what portion is due to the additive effect of the persisting compression is not fully known. There have been only two previous experimental studies of this question. Tarlov (Tarlov, 1954; Tarlov and Klinger, 1984) applied an epidural balloon to injure the canine thoracic spinal cord, and concluded that persisting compression adversely affected neurological function, and this led him to advocate immediate decompression as a treatment. Our laboratory (Dolan, Tator, Endrenyi, 1980) examined the above question with the clip compression injury model in the rat at C7-T1 with clip strengths of 16,17 and $178 \mathrm{gm}$, and times until decompression of 3 to 900 seconds. It was found that early relief of persisting compression produced improved neurological recovery for all the compression forces studied. In contrast to our previous study, the current study used times until decompression ranging from 15 to 240 minutes in an attempt to simulate the delays between trauma and treatment relevant to the management of patients with spinal cord injuries. Spinal cord injury units are achieving average trauma to admission delays of approximately 4 to 5 hours (Tator, Rowed, et al., 1984), although in most cases, admission to the initial hospital was within 1 to 2 hours. Decompression of the cord by traction or pharmacological agents could be instituted at the initial hospital after pre- 
liminary diagnostic tests and stabilisation of the patient. Thus, the 15 minute to 4 hour delays until decompression in the present study are relevant to those in the clinical setting.

Lower forces of compression $(2 \cdot 3,16.9,53.0 \mathrm{gm})$ were used in the present study compared to the previous study (Dolan, Tator, Endrenyi, 1980) in order to examine the injuries for which decompression after the longer trauma to treatment delays would still be beneficial. In the former study, the animals injured by the $178 \mathrm{gm}$ clip and in whom 300 seconds elapsed until decompression showed poor function on the inclined plane and were only slightly better than those with a segment of the spinal cord removed $\left(35.0 \pm 4.5^{\circ}\right.$ vs $23.0 \pm 2.5^{\circ}$ ). If injury forces of this magnitude had been used in the present study in which the minimal time until decompression was 15 minutes, the initial injury force would have been too severe for decompression to be beneficial.

In the present study, the normal animals achieved similar angles on the inclined plane $\left(81.4 \pm 1.8^{\circ}\right)$ as compared to the previous study (Dolan, Tator, Endrenyi, 1980). The lower limit of performance (the animals with transection) in the present study was $29 \cdot 2 \pm 2 \cdot 2^{\circ}$ which was higher, though not significantly $\left(\mathrm{p}>\cdot 05\right.$ ), from $23 \cdot 0 \pm 2.5^{\circ}$ found previously (Dolan, Tator, Endrenyi, 1980). The slightly higher value is likely because the spinal cord was only transected in the present study whereas previously a $5 \mathrm{~mm}$ segment of spinal cord was completely removed (myelotomy).

The clip strengths chosen in the present study delivered a spectrum of injury extending from light to severe as can be seen in Figure 5 where the clips have been applied around a freshly harvested rat spinal cord. This difference in gross appearance correlated well with the functional results on the inclined plane: after 15 minutes of compression the animals injured by the $2.3 \mathrm{gm}$ and $53.0 \mathrm{gm}$ clips achieved $65.4 \pm 0.9^{\circ}$ and $30.9 \pm 1 \cdot 1^{\circ}$ respectively (Table I). The current study proves that acute decompression of the cord even after prolonged compression durations, as long as 4 hours, which are relevant to those found in clinical practice, may still be beneficial in patients with acute spinal cord injury of minimal to moderate severity. For example, animals injured by the $2.3 \mathrm{gm}$ clip performed significantly better on the inclined plane if they were decompressed after 15 or 60 minutes as compared with the longer compression durations. Similarly, animals injured by the $16.9 \mathrm{gm}$ clip were functionally better if they were decompressed at 15 minutes compared with the longer durations. However, at the highest injury force of $53.0 \mathrm{gm}$, decompression even at 15 minutes was not beneficial. For each compression duration there was an 'impact force threshold' below which the cord may still improve with early decompression after a given period of persisting compression. For example, the threshold for the animals decompressed with 15 minutes was between 16.9 and $53.0 \mathrm{gm}$ while the threshold for the longer times until decompression was between 2.3 and 16.9 gms. With the very short times until decompression studied previously (Dolan, Tator, Endrenyi, 1980) the 'impact force threshold' was much greater. For example, if decompression was undertaken within 3 seconds of a $178 \mathrm{gm}$ injury force, the animals achieved $42.3 \pm 1 \cdot 4^{\circ}$, which was significantly better than the myelectomy group $\left(23 \cdot 0 \pm 2 \cdot 5^{\circ}\right)(\mathrm{p}<\cdot 05)$.

What determines this 'impact force threshold' for a given time until decompression is an interesting question. It is still uncertain whether the extent 
of recovery after spinal cord injury is related to the initial mechanical disruption caused by the impact and persisting compression or to other secondary pathophysiological mechanisms such as post-traumatic ischaemia (Allan, 1914; Balentine, 1978; White, 1975). Tarlov, and later Kobrine and others concluded that ischaemia was not a crucial factor and they based their conclusion on evidence such as recovery times and changes in somatosensory evoked potentials which they considered incompatible with an ischaemic etiology (Geflan, Tarlov, 1955; Kobrine, Evans, Rizzoli, 1978; Tarlov, 1972). However, other authors including ourselves have documented with several techniques that spinal cord blood flow (SCBF) is markedly decreased after trauma (Dohrmann, Wagner, Bucy, 1972; Sandler, Tator, 1976; White, 1975). Furthermore, pathological and direct microvascular studies have convincingly proved that ischemia is a significant pathophysiological mechanism after spinal cord injury (Allan, 1914; Balentine, 1978; Dohrmann, Wagner, Bucy, 1972; Tator, Rowed, 1979; Turnbull). Recent studies have shown a multitude of other post-traumatic secondary biochemical alterations including accumulation of intracellular calcium, free radical generation, superoxides, etc. (Balentine, 1978; Gelfan, Tarlov, 1955; White, 1975), which may also contribute to the injury process. The additional damage which might be caused by post-traumatic ischaemia or these other, secondary mechanisms is not immediate but develops with time, and therefore it is possible that stopping their progression would improve the likelihood of neurological recovery. The present study strongly supports this view.

The initial impact on the spinal cord may cause shearing of axons, rupture of thin walled veins, mainly in the grey matter, and ultimately produces haemorrhage and oedema (Allan, 1914; Dohrmann, Wagner, Bucy, 1972; Sandler, Tator, 1976; Wagner, 1981). These are dose dependent, and in keeping with the current finding that clip strength was the main determinant of neurological recovery. Eidelberg et al. (1976), showed that there was little correlation between neurological function and the extent of the pathological changes found after experimental spinal cord injury, and that even a small amount of surviving cord tissue was compatible with a considerable amount of neurological function. In this regard, it should be noted that complete transection of the spinal cord is rare in civilian spinal cord trauma, and thus there may be some surviving salvageable tissue even after major injury. The amount of salvageable function is of course inversely related to the dose of injury, and persisting compression may cause progression of the vascular or other, secondary mechanisms discussed above, which may irreversibly eliminate any potential for recovery. For example, if the cord was decompressed within 15 minutes after the 2.3 or 16.9 gm injury, there would be less progression of the secondary mechanisms due to persistent compression. The longer times until decompression allowed propagation of the injury process, and therefore lowered the 'impact force threshold' of the initial impact.

The decision whether a given patient would benefit from early decompression requires a knowledge of whether the initial impact injury force has surpassed the 'impact force threshold' for that particular duration of persisting compression. The present study has shown that patients with injuries of minimal to moderate force would potentially benefit while those with severe injuries would not. Unfortunately, in clinical practice it is not possible to determine the exact 
magnitude of the initial impact force although knowledge of the circumstances in which an injury occurred, the clinical examination, and neurophysiological and radiological data may provide some evidence of the severity of the injury. In clinical practice, patients with immediate, and complete motor and sensory loss below the level of the cord injury who fail to improve within four hours or so, have likely sustained injuries above the threshold. In the authors' opinion these cases would be extremely unlikely to show neurological recovery of cord function if they were decompressed. Conversely, partial cord injuries with some preservation of motor and sensory function below the level of injury have likely sustained a below threshold injury and should be considered candidates for early decompression if they have demonstrable persisting compression of the cord.

\section{Conclusions}

The ultimate neurological deficit after experimental spinal cord trauma is determined both by the severity of the initial impact force and by the duration of persisting compression, with the magnitude of the initial impact force being the dominant factor.

Decompression of the spinal cord after durations of persisting compression up to 4 hours simulating those encountered in clinical practice, may enhance neurological recovery providing the severity of the initial impact is below the 'impact force threshold' for that compression duration.

Determination of the initial impact force in the clinical setting is the main problem in selecting which patients may benefit from early decompression.

\section{Acknowledgement}

The authors are grateful to Mrs L. Marmash, Mrs Elizabeth Forsythe and Mr Jerald Ohasi for their assistance. Support for this work was provided by the Medical Research Council, Grant No. MT4046. A. Guha was a Fellow of the Medical Research Council of Canada during the period of this research. I. Piper was a Research Assistant during the period of this study.

\section{References}

Allen A 1914 Remarks on the histophatological changes in the spinal cord due to impact. An experimental study. Fournal of Nervous and Mental Disease 41:141-147.

BALENTINe DJ 1978 Pathology of experimental spinal cord trauma. The necrotic lesion as a function of vascular injury. Laboratory Investigation 39:236-253.

DohrmanN JG, WAGNER CF, BUCY CP 1972 Transitory traumatic paraplegia: electron microscopy of early alterations in myelinated nerve fibres. Fournal of Neurosurgery 36:407-415.

DolAN EJ, TATOR CH, ENDRENYI L 1980 The value of decompression after acute experimental spinal cord compression injury. Fournal of Neurosurgery 53:749-755.

Dolan EJ, TATOR CH 1979 A new method for testing the force of clips for aneurysms on experimental spinal cord compression. Fournal of Neurosurgery 51:229-233.

DUCKER BT, HAMIT FH 1969 Experimental treatments of acute spinal cord injury fournal of Neurosurgery 30:693-697.

DuCKer BT, Saloman M, Daniell BH 1978 Experimental spinal cord trauma III: Therapeutic effect of immobilization and pharmacological agents. Surgical Neurology 10:71-76

DUCKER BT, BELlegarRigue R, SAlOMAN M et al. 1984 Timing of operative care in cervical spinal cord injury. Spine 9:525-531.

EIDELBERG, StATEN E, Walkins JC et al. 1976 A model of spinal cord injury. Surgical Neurology 5:35-38. 
GeLFAN S, TARLOV MI 1955 Differential vulnerability of spinal cord structures to anoxia. Fournal of Neurophysiology 18:170-188.

KoBRINE IA, Evans ED, Rizzoli H 1978 Correlation of spinal cord blood flow and function in experimental compression. Surgical Neurology 10:54-59.

RIVLIN AS, TATOR CH 1978 Effect of duration of acute spinal cord compression in a new acute cord injury model in the rat. Surgical Neurology 10:39-43.

Rivin AS, TATOR CH 1977 Objective clinical assessment of motor function after experimental spinal cord injury in the rat. Fournal of Neurosurgery 47:577-581.

SANDLER AN, TATOR CH 1976 Review of the effect of spinal cord trauma on the vessels and blood flow in the spinal cord. Fournal of Neurosurgery 45:638-646.

STAUFFER SE 1975 Diagnosis and prognosis of acute cervical spinal cord injury. Clinical Orthopaedics \& Related Research 112:9-15.

TARLOV MI 1972 Acute spinal cord compression paralysis. Fournal of Neurosurgery 36:10-20.

TARLOV MI, KLINGER H, Vitale S 1953 Spinal cord compression studies. I. Experimental techniques to produce acute and gradual compression. Archives of Neurology and Psychiatry 70:813819.

TARLOV MI, KLINGER H 1954 Spinal cord compression studies II: Time limits for recovery after acute compression in dogs. Archives of Neurology and Psychiatry 71:271-290.

TARLOV MI, 1954 Spinal cord compression studies III: Time limits for recovery after gradual compression in dogs. Archives of Neurology and Psychiatry 71:588-597.

TATOR CH, RowED DW 1979 Current concepts in the immediate management of acute spinal cord injuries. Canadian Medical Association fournal 121:1453-1464.

TATOR CH, ROWED DW et al. 1984 Management of acute spinal cord injuries. Canadian fournal of Surgery 27:289-296.

TURNBULL IM Blood supply of the spinal cord: Normal and pathological considerations. Clinical Neurosurgery 20: Chap. 5, p. 55-84.

WAGNER FC, STEWARD WB 1981 Effect of trauma dose on spinal cord edema. Fournal of Neurosurgery 54:802-806.

WHITE RJ 1975 Pathology of spinal cord injury in experimental lesions. Clinical Orthopaedics Related Research 112:16-26. 